\title{
A syndrome of severe idiopathic pulmonary parenchymal disease with pulmonary hypertension in Pekingese
}

This article was published in the following Dove Press journal:

Veterinary Medicine: Research and Reports

23 February 2016

Number of times this article has been viewed

\author{
Liza S Köster ${ }^{1}$ \\ Robert M Kirberger ${ }^{2}$ \\ 'Section of Medicine, Department \\ of Clinical Sciences, Integrative \\ Mammalian Research (IMR) Center, \\ Ross University School of Veterinary \\ Medicine (RUSVM), Basseterre, St \\ Kitts, West Indies; ${ }^{2}$ Diagnostic Imaging \\ Section, Department of Companion \\ Animal Clinical Studies, Faculty of \\ Veterinary Science, University of \\ Pretoria, Onderstepoort, South Africa
}

\begin{abstract}
This paper describes 35 Pekingese dogs with a syndrome characterized by dyspnea, cyanosis, episodic syncope, soft pulmonary "velcro" crackles, pulmonary hypertension (PH), and computed tomography and radiographic changes consistent with pulmonary parenchymal disease. The medical data base was searched with the criteria "Pekingese" and "syncope" or "dyspnea" or "tachypnea" or "pulmonary hypertension", over a 36-month period. Inclusion criteria were echocardiographic changes consistent with noninvasive diagnosis of $\mathrm{PH}$, either subjectively by B-mode or objectively by Doppler. Dogs were excluded $(n=106)$ if there were insufficient or poor-quality radiographic or echocardiographic records or if diseases other than chronic pulmonary disease were found to be the etiology. The records of $35 \mathrm{dogs}$ met these criteria and presented with a respiratory crises preceded by a history of chronic exercise intolerance and episodic syncope. The average age was 14.5 years (range: 7-19 years), with 21 males and 14 females. Most of the dogs had an interstitial lung pattern with radiographic evidence of right heart enlargement. There was a $77 \%(n=27)$ mortality and a median survival of 60 days (interquartile range: 9-210 days). This study highlights a cor pulmonale syndrome from $\mathrm{PH}$ due to chronic pulmonary parenchymal disease, with a grave prognosis, in middle-aged to geriatric population of Hong Kong Pekingese.
\end{abstract}

Keywords: computed tomography, interstitial lung disease, dog, syncope

\section{Introduction}

Pulmonary parenchymal disease includes diseases of the alveoli, microvasculature, and interstitial tissue. ${ }^{1}$ Interstitial lung diseases (ILDs) are a group of poorly defined diseases with pathology largely limited to the interstitial space between the basement membrane and the capillaries (alveolitis) but can extend to the peribronchiolar region. ${ }^{2}$ The proposed pathogenesis is irritation of the alveolar epithelial lining, specifically type I alveolar epithelial cells (inhaled or hematogenous), triggering a host inflammatory response (profibrocyte and pro-inflammatory cytokine release) with subsequent deposition of extracellular matrix and fibrosis. ${ }^{3}$ Fibrin formation is critical in the pathogenesis of these diseases, and abnormal fibrinolysis could play a role as does an imbalance of matrix metalloproteinases and tissue metalloproteinase inhibitors. ${ }^{4}$

Pulmonary hypertension (PH) is characterized by historical findings that include lethargy and reduced exercise tolerance, cough, dyspnea, syncope, and clinical signs that include a diastolic pulmonary valve murmur, systolic murmurs, adventitious lung sounds, cyanosis, and jugular venous distension. ${ }^{5}$ The clinical definition of $\mathrm{PH}$ is a persistent mean and systolic pulmonary pressure exceeding 20 and $30 \mathrm{mmHg}$, respectively, as measured by cardiac catheterization or indirectly using Doppler-derived
Correspondence: Liza S Köster Section of Medicine, Department of Clinical Sciences, Integrative Mammalian Research (IMR) Center, Ross University School of Veterinary Medicine (RUSVM) PO Box 334, Basseterre, St Kitts, West Indies

Tel +869465 4161×410 I312

Email Ikoster@rossvet.edu.kn
Veterinary Medicine: Research and Reports 2016:7 19-31

(c) (1) (9) $\odot 2016$ Köster and Kirberger. This work is published and licensed by Dove Medical Press Limited. The full terms of this license are avalabble at https:/wwrw.dovepress. cc. the work you hereby accept the Terms. Non-commercial uses of the work are permitted without any further permission from Dove Medical Press Limited, provided the work is properly attributed. For permission for commercial use of this work, please see paragraphs 4.2 and 5 of our Terms (https://www.dovereress.com/terms.php).
Dovepress

http://dx.doi.org// 0.2147/VMRR.S92729

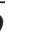

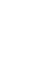


measure of a tricuspid regurgitation velocity of $\geq 2.8 \mathrm{~m} / \mathrm{s}$ or a pulmonary insufficiency of velocity of $\geq 2.2 \mathrm{~m} / \mathrm{s}$ in the absence of tricuspid valve dysplasia or pulmonic stenosis, respectively. ${ }^{5,6} \mathrm{PH}$ has been described as a complication of a number of idiopathic or secondary cardiopulmonary diseases. ${ }^{7}$ A classification system categorizes the etiologies into idiopathic or secondary, which are further grouped according to anatomical location, precapillary, capillary, or postcapillary. ${ }^{5,8}$ Precapillary etiologies include congenital systemic to pulmonary shunts (atrial septal defects, ventricular septal defects, and patent ductus arteriosus), heartworm disease, pulmonary thromboembolism (caused by immune-mediated hemolytic anemia, neoplasia, hyperadrenocorticism, early phase of disseminated intravascular coagulation, or trauma), or direct compression of pulmonary arteries by granulomas or neoplasia. Capillary causes include chronic obstructive pulmonary disease, interstitial pulmonary fibrosis, neoplasia, high altitude disease, and reactive pulmonary vascular resistance. Postcapillary cause is left-sided heart disease (mitral valve disease, myocardial disease). The pathophysiology of $\mathrm{PH}$ is multifactorial, and proposed mechanisms include alveolar hypoxia with reflex vasoconstriction, release of antithrombin, activated clotting cascade, platelet-mediated vascular remodeling, vasoconstriction (thromboxane, histamine, serotonin, and endothelin 1), retarded vasodilation (decreased nitrous oxide, prostacycline, endothelin relaxing factor), and primary pulmonary pathological processes and inflammation. ${ }^{7}$ In heartworm disease and systemic pulmonary shunts, the mechanism is intimal proliferation and fibrosis due to release of parasite toxins in the former and shear stress from increased blood velocities in the latter. In pulmonary or airway disease, hypoxia induces reflex vasoconstriction, and hypoxemia-induced polycythemia can contribute to shear stress. In left-sided heart disease, the cause is simple mechanics of increased pulmonary capillary wedge pressure.

This study investigates the historical, clinical, radiographic, computed tomography (CT), and clinical pathological findings in Pekingese dogs suffering from $\mathrm{PH}$ and chronic, clinically progressive, idiopathic pulmonary parenchymal disease thought to be ILD. A lung pathological involvement severity scoring system was utilized to indirectly assess lung pathology objectively on thoracic radiographs and CT.

\section{Materials and methods}

\section{Animals}

For this retrospective study, medical records of all dogs presented to Peace Avenue Veterinary Clinic, Hong Kong, between October 1, 2009, and September 30, 2012, were searched for cases of Hong Kong Pekingese dogs diagnosed with respiratory disease consistent with lower airway disease that had accompanying PH confirmed on echocardiography.

Ethics approval and owner consent was not required as this was a retrospective study, no animal was subjected to an intervention, and lastly, owner information was not recorded.

\section{Inclusion criteria}

The search criteria used included "Pekingese" and "syncope" or "collapse" or "cyanosis" or "pulmonary hypertension" or "interstitial lung pattern". Medical records were reviewed in detail, and only those cases with complete medical records, including history, complete blood count, serum biochemistry results, and thoracic radiographs, were included. Data were entered using Excel spreadsheets. If CT, bronchoscopy, and bronchoalveolar lavage (BAL) were performed, the results were included. Blood gas analyses were infrequently performed and were not included in the study. The signalment was determined by the written medical record. Historical findings of exercise intolerance, cyanosis, dyspnea, syncope, and coughing were recorded, and if possible, the duration of the preceding clinical signs prior to presentation was calculated. The reason for seeking veterinary opinion was recorded.

In order to include as many possible cases with this syndrome, it was necessary to include both objective (Doppler) and subjective (B-mode and M-mode) echocardiographic diagnoses of $\mathrm{PH}$. Echocardiography included two-dimensional (B-mode) M-mode, and in a few cases Doppler interrogation of the valves using standard views in unsedated dogs using either a MYLAB 30 vet (Esoate, Italy) or a GE Vivid E9 (General Electric Co., GE Vingmend Ultrasound A/S, Horten, Norway). Many examinations were abbreviated due to severe respiratory compromise. Studies were performed using a 6-9 MHz probe for the MYLAB 30 vet and the $6 \mathrm{~S}-\mathrm{D}(2.7-8 \mathrm{MHz})$ and $12 \mathrm{~S}-\mathrm{D}$ (4-12 MHz) probe for the GE Vivid E9. All Digital Imaging and Communications in Medicine (DICOM) still and cine images were reviewed by the primary investigator. For those dogs in which objective inclusion criteria (Doppler) were used $(n=9)$, right ventricular (RV) to right atrial pressure gradient was calculated by application of the modified Bernoulli equation $\left(\Delta P=4 \times\right.$ velocity $\left.^{2}\right)$ to the maximal tricuspid regurgitation velocity. A peak tricuspid regurgitation of $\geq 2.8 \mathrm{~m} / \mathrm{s}$ was considered indicative of $\mathrm{PH}$. In the absence of Doppler interrogation $(n=26)$, a combination of subjective inclusion criteria was used to define moderate-to-severe $\mathrm{PH}$ as follows: RV hypertrophy and dilation, decreased left ventricular size and flattening, or paradoxical septal motion of the interventricular septum..$^{5,9}$ 


\section{Exclusion criteria}

Exclusion criteria included Pekingese with concurrent chronic mitral valvular disease classified according to the American College of Veterinary Internal Medicine (ACVIM) consensus statement B2 or higher, Dirofilaria immitis infection, pulmonic valve stenosis, and uncorrected patent ductus arteriosus. ${ }^{10}$ If the dog was not on regular heartworm prophylaxis, then only if a $D$. immitis ELISA antigen test (SNAP ${ }^{\circledR}$, Heartworm RT test, IDEXX) was found to be negative at the time of diagnosis, could the dog be included in the study. Pulmonic valve stenosis was ruled out echocardiographically based on lack of deformity or narrowing of the pulmonic valve region, absence of poststenotic dilation of the pulmonary artery, normal excursion of the valve leaflets, and no high-velocity turbulent systolic pulmonary artery flow if Doppler was performed.

\section{Clinical findings}

Clinical examination results for the first consultation, including body weight $(\mathrm{kg})$, heart rate (beats per minute[bpm]), respiratory rate (breaths per minute[bpm]), rectal temperature $\left({ }^{\circ} \mathrm{C}\right)$, cyanosis of the mucous membranes, respiratory description (dyspnea), and the presence of, and if recorded the type of, crackles audible on auscultation of the lungs were recorded. Venous blood was collected for complete blood counts (Procyte Dx® Hematology Analyzer, IDEXX $\operatorname{VetLab}^{\circledR}$, Westbrook, ME, USA) and serum biochemistry analyses (Catalyst ${ }^{\circledR}$, Chemistry Analyzer, IDEXX VetLab) as part of the initial investigation.

\section{Diagnostic imaging}

Standard thoracic radiographs (right lateral and dorsoventral thoracic views) were acquired using direct digital radiography technique (Definium ${ }^{\mathrm{TM}} 8000 \mathrm{X}$-ray system, General Electric Company, Waukesha, WI, USA), and electronic calipers were used for measurements that were made from the outer surface of vessels or bronchi. The primary investigator evaluated the thoracic radiographs, including cardiac silhouette chamber enlargement, lung pattern and distribution, pulmonary artery-to-adjacent vein ratios at the level of the fourth intercostal space on the lateral views for the left cranial lobar pulmonary artery (CrPA) and vein (CrPV), and the ninth intercostal space on dorsoventral view for the caudal lobar pulmonary artery (CdPA) and vein (CdPV). Vertebral heart score and the diameter of the caudal vena cava were measured on the lateral views as well as an assessment of whether the cardiac apex was elevated, an indication of RV wall concentric hypertrophy, and if present then classified subjectively as either mild, moderate, or severe based on the degree of "lifting" of the apex from the sternum. Arteries and veins were measured perpendicular to the vessel at the thickest diameter. A lung pathological involvement severity scoring system was developed. Each lung lobe (right cranial, right middle, right caudal, and accessory and left cranial pars cranialis and pars caudalis and left caudal) was allocated a score (0-3) depending on severity and extent of lung pattern, with the score of 1 indicating mild (interstitial pattern) and the score of 3 indicating severe lung involvement (alveolar pattern). A cumulative lung severity score (0-21) was the sum of the seven individual lung lobe scores.

Survey and postcontrast CT images were acquired by a manual injection of iohexol (Omnipaque, GE Healthcare Inc., Waukesha, WI, USA) at a dose of $600 \mathrm{mg} \mathrm{I} / \mathrm{kg}$. CT was performed with the dog in sternal recumbency under general anesthesia, using a helical dual slice scanner (General Electric Co., GE Health Care, CT Goldseal Hispeed NXI, Waukesha, WI, USA) with a sliding table and fixed gantry. The standard protocol was to ensure that dogs remained in sternal recumbency prior to $\mathrm{CT}$ to avoid atelectasis. Dogs were imaged from caudal to cranial with a slice thickness of $2 \mathrm{~mm}$. A manual breath-hold technique was performed by the primary investigator, observing health and safety standards (lead-lined gown, gloves, thyroid shield, and a protective body shield) inflating the lung to an inspiratory pressure of between 10 and $15 \mathrm{~cm}$ water for a scan time of $<60$ seconds. Images were sequential $2 \mathrm{~mm}$ collimated transverse images using lung algorithms. Analysis of the DICOM images was performed on a dedicated viewing station by a board-certified radiologist and the primary investigator using commercially available software (K-PACS, IMAGE Information Systems Ltd., London, UK). A semiobjective $\mathrm{CT}$ nonaeration lung index was developed by evaluating the Hounsfield unit (HU) of each lung lobe on a representative transverse slice of the worst affected part of the lobe. Taking the $\mathrm{HU}$ of normal lung as -713 , a percentage decreased aeration was determined for each lobe, and then the contribution of each lobe to the total lung volume ${ }^{11}$ was taken into consideration to determine a total lung aeration loss for each dog stated as a pathological lung index score with $0=$ normal and $100=$ all lungs consolidated. These data were also compared to the more subjective radiologically determined percentage of lung involvement. The main pulmonary artery diameter (dMPA), measured on transverse view at just distal to the bifurcation, and ascending aorta diameters (dAas) were measured using electronic calipers on the same transverse slice, and a ratio was determined. Internal bronchial lumento-adjacent pulmonary arterial (BA) ratios were measured as 
described previously. ${ }^{12}$ The right and left internal ventricular diameters at their maximum width on a transverse image were measured, and the right-to-left ratio was determined.

\section{Bronchoscopy and BAL}

Bronchoscopy was performed after imaging and under the same anesthetic used for the CT. A $2.8 \mathrm{~mm}$ flexible bronchoscope (BF-XP160F; Olympus Corporation, Tokyo, Japan) was used followed by a blind BAL of the right caudal lung lobe using an 8 -FG red rubber feeding tube and $20 \mathrm{~mL}$ of sterile saline. The lavage fluid was submitted for cytology, aerobic and fungal culture, and sensitivity. Quantitative cultures were not available.

\section{Outcome}

The time from first diagnosis until recorded time of death ascribable to $\mathrm{PH}$ complications was recorded as survival time. If the dog was still alive at the end of the investigation period, it was marked as alive. Treatments prescribed for the management of ILD or PH were noted, with dosages and dosing intervals.

\section{Statistics}

Bayesian descriptive statistics were used. Excel software was used to calculate the means or the medians and interquartile range (IQR) of the continuous data depending on the distribution of the data.

\section{Results}

\section{Animals and clinical findings}

A total of 141 Pekingese with respiratory disease and $\mathrm{PH}$ were identified on the medical records based on the search criteria, from which 106 dogs were excluded based on the criteria described. The signalment, historical and clinical signs, and outcome for the individual dogs are summarized in Table 1.

The mean age of the remaining 35 Pekingese was 14.5 years (range: 7-19 years), with 21 males and 14 females. The average body mass was $5.65 \mathrm{~kg}$ (range: $3.1-9 \mathrm{~kg}$ ). Only 16 of the 35 dogs had a history of a mild chronic cough, but $24 \operatorname{dogs}$ had a history of at least one or more episodes of syncope, and in $30 \mathrm{dogs}$, there was description of exercise intolerance by the owner. The onset of clinical signs preceded presentation by a median of 60 days (IQR 4.5-255 days). The clinical signs at presentation included dyspnea (71\%) and cyanosis (40\%). Twenty-nine dogs (83\%) had audible crackles on auscultation located caudodorsally, both uni- and bilaterally. These were described as soft and classified as "velcro" crackles by the primary author who was responsible for managing the majority of the dogs included in the study. Vital parameters recorded at presentation included median heart rate (125 bpm; IQR 120-155 bpm), respiratory rate (42 bpm; IQR 25-66 bpm), and rectal temperature $\left(38.4^{\circ} \mathrm{C}\right.$; IQR $37.7^{\circ} \mathrm{C}-38.6^{\circ} \mathrm{C}$ ). Mild, nonregenerative normocytic, normochromic anemia was detected in two dogs on hematology. Moderately increased, blood urea nitrogen (37 mmol/L, reference interval 2.5-9.6 mmol/L) and alanine aminotransferase (226 U/L, reference interval 10-100 U/L) were found in one of the dogs with anemia. The latter dog had ascites that was a modified transudate (fluid analysis, total protein $44 \mathrm{~g} / \mathrm{L}$, low cell count) believed to be from right heart failure.

\section{Diagnostic imaging}

The predominant radiographic lung pattern was diffuse interstitial $(n=20)$ to bronchointerstitial $(n=7)$ or patchy alveolar patterns $(n=1)$ (Figures 1 and 2$)$. Seven dogs $(20 \%)$ had normal appearing lungs. The median cumulative radiographic lung severity score was 3 (IQR 1.75-4). The cardiac silhouette had evidence of right heart enlargement in 23 dogs (66\%) with a median vertebral heart score of 9.5 (IQR 9-10.5). The cardiac apex was elevated on the right lateral thoracic radiograph to a minor extent in ten dogs, moderately in four dogs, and severely in six dogs (Figure 2). The median CrPA and CdPA to vein ratio (PA/PV) was 1.1 (IQR 0.97-1.4; n=21) and 1.0 (IQR 1.0-1.3; n=18) measured on the lateral and dorsoventral thoracic radiographs, respectively, in those dogs that the measurement could be made.

CT was performed in five dogs. The following pathology was present: parenchymal bands $(n=3)$, moderate subpleural interstitial thickenings $(n=2)$, moderate peribronchiolar interstitial thickening $(n=4)$, nodules $(n=1)$, consolidated lung obscuring vessels $(n=2)$, traction bronchiectasis $(n=3)$, calcification $(n=2)$, and honeycombing $(n=3)$ (Figures 3 and 4). The mean dMPA was $12.1 \mathrm{~mm}$ (range: 9.5-17.2 mm; $\mathrm{n}=5$ ) and dAa was $10.7 \mathrm{~mm}$ (range: $8.4-12.5 \mathrm{~mm}$; $=5$ ), and the ratio was 1.1 (range: 0.76-1.63) (Figure 5). The mean BA $(n=6)$ was 0.72 (range: $0.5-0.93$ ). In only three dogs could the ventricular internal diameters be measured. The internal diameter of the right ventricle was on average $106 \%$ the size of the left ventricle (range: $97 \%-118 \%$ ). The mean of the total CT nonaeration lung index was 25.3 (range: 8.5-43.3). The findings in the five dogs that underwent both thoracic radiography and CT are described in Table 2. 
Table I Signalment, historical, clinical findings and outcome in 35 Pekingese with chronic pulmonary disease

\begin{tabular}{|c|c|c|c|c|c|c|c|}
\hline $\begin{array}{l}\text { Case } \\
\text { number }\end{array}$ & Sex & $\begin{array}{l}\text { Body mass } \\
(\mathrm{kg})\end{array}$ & $\begin{array}{l}\text { Age } \\
\text { (years) }\end{array}$ & $\begin{array}{l}\text { Historical and } \\
\text { clinical findings }\end{array}$ & $\begin{array}{l}\text { Duration of clinical } \\
\text { signs prior to } \\
\text { presentation (days) }\end{array}$ & $\begin{array}{l}\text { Radiological } \\
\text { cumulative } \\
\text { lung score }^{\mathrm{a}}\end{array}$ & $\begin{array}{l}\text { Survival (days) } \\
\text { from date of } \\
\text { diagnosis }\end{array}$ \\
\hline I & Male & 4.20 & 18 & $\begin{array}{l}\text { Exercise intolerance, } \\
\text { tachypnea, dyspnea, } \\
\text { syncope, cyanosis, } \\
\text { crackles }\end{array}$ & 7 & 1 & 25 \\
\hline 2 & Male & 4.10 & 9 & $\begin{array}{l}\text { Exercise intolerance, } \\
\text { syncope, cyanosis, } \\
\text { crackles, heart murmur }\end{array}$ & 365 & 0 & 4 \\
\hline 3 & Male & 7.20 & 10 & $\begin{array}{l}\text { Exercise intolerance, } \\
\text { cough, tachypnea, } \\
\text { dyspnea, syncope, } \\
\text { cyanosis, crackles, } \\
\text { heart murmur }\end{array}$ & 4 & 10 & 60 \\
\hline 4 & Male & 5.40 & 13 & $\begin{array}{l}\text { Exercise intolerance, } \\
\text { syncope, cyanosis, crackles, } \\
\text { heart murmur }\end{array}$ & 2 & 0 & 6 \\
\hline 5 & Male & 5.70 & 15 & $\begin{array}{l}\text { Exercise intolerance, } \\
\text { tachypnea, syncope, } \\
\text { cyanosis, crackles }\end{array}$ & 14 & 4 & 210 \\
\hline 6 & Male & 6.30 & 16 & $\begin{array}{l}\text { Exercise intolerance, } \\
\text { tachypnea, dyspnea, } \\
\text { syncope, cyanosis, } \\
\text { crackles, heart murmur }\end{array}$ & 180 & 6 & 60 \\
\hline 7 & Male & 5.00 & 15 & $\begin{array}{l}\text { Exercise intolerance, } \\
\text { syncope, dyspnea, } \\
\text { cyanosis, crackles, } \\
\text { heart murmur }\end{array}$ & 330 & 3 & 30 \\
\hline 8 & Male & 9.00 & 8 & $\begin{array}{l}\text { Exercise intolerance, cough, } \\
\text { tachypnea, dyspnea, syncope, } \\
\text { cyanosis, crackles, heart } \\
\text { murmur }\end{array}$ & 30 & 3 & 30 \\
\hline 9 & Female & 3.80 & 9 & $\begin{array}{l}\text { Exercise intolerance, } \\
\text { tachypnea, dyspnea, } \\
\text { cyanosis, crackles, } \\
\text { heart murmur }\end{array}$ & 5 & 12 & 20 \\
\hline 10 & Male & 7.00 & 13 & $\begin{array}{l}\text { Exercise intolerance, } \\
\text { cough, tachypnea, } \\
\text { syncope, cyanosis, } \\
\text { heart murmur }\end{array}$ & 60 & 5 & 3 \\
\hline II & Female & 6.30 & 7 & $\begin{array}{l}\text { Exercise intolerance, } \\
\text { tachypnea, dyspnea, } \\
\text { cyanosis, crackles, } \\
\text { heart murmur }\end{array}$ & 365 & 7 & 180 \\
\hline 12 & Male & 4.90 & 9 & $\begin{array}{l}\text { Exercise intolerance, } \\
\text { tachypnea, dyspnea, } \\
\text { syncope, cyanosis, } \\
\text { crackles, heart murmur }\end{array}$ & 180 & 2 & 210 \\
\hline 13 & Female & 6.20 & 13 & $\begin{array}{l}\text { Exercise intolerance, } \\
\text { tachypnea, dyspnea, } \\
\text { syncope, cyanosis, } \\
\text { crackles }\end{array}$ & 2 & 2 & 1 \\
\hline 14 & Female & 4.90 & 14 & $\begin{array}{l}\text { Exercise intolerance, } \\
\text { tachypnea, dyspnea, } \\
\text { heart murmur }\end{array}$ & 120 & 0 & 420 \\
\hline
\end{tabular}


Table I (Continued)

\begin{tabular}{|c|c|c|c|c|c|c|c|}
\hline $\begin{array}{l}\text { Case } \\
\text { number }\end{array}$ & Sex & $\begin{array}{l}\text { Body mass } \\
(\mathrm{kg})\end{array}$ & $\begin{array}{l}\text { Age } \\
\text { (years) }\end{array}$ & $\begin{array}{l}\text { Historical and } \\
\text { clinical findings }\end{array}$ & $\begin{array}{l}\text { Duration of clinical } \\
\text { signs prior to } \\
\text { presentation (days) }\end{array}$ & $\begin{array}{l}\text { Radiological } \\
\text { cumulative } \\
\text { lung score }^{\mathrm{a}}\end{array}$ & $\begin{array}{l}\text { Survival (days) } \\
\text { from date of } \\
\text { diagnosis }\end{array}$ \\
\hline 15 & Female & 6.20 & 12 & $\begin{array}{l}\text { Exercise intolerance, } \\
\text { cough, tachypnea, } \\
\text { dyspnea, crackles, } \\
\text { heart murmur }\end{array}$ & 3 & 4 & 690 \\
\hline 16 & Female & 8.30 & 12 & $\begin{array}{l}\text { Exercise intolerance, } \\
\text { tachypnea, dyspnea, } \\
\text { syncope, cyanosis, } \\
\text { crackles, heart murmur }\end{array}$ & I & 10 & 4 \\
\hline 17 & Male & 6.20 & 12 & $\begin{array}{l}\text { Exercise intolerance, } \\
\text { cough, dyspnea, } \\
\text { syncope, crackles, } \\
\text { heart murmur }\end{array}$ & 730 & 0 & 270 \\
\hline 18 & Male & 6.20 & 16 & $\begin{array}{l}\text { Exercise intolerance, } \\
\text { cough, tachypnea, } \\
\text { dyspnea, syncope, } \\
\text { cyanosis, crackles, } \\
\text { heart murmur }\end{array}$ & I & 3 & 11 \\
\hline 19 & Female & 5.60 & 14 & $\begin{array}{l}\text { Exercise intolerance, } \\
\text { cough, tachypnea, } \\
\text { dyspnea, syncope, } \\
\text { cyanosis, crackles, } \\
\text { heart murmur }\end{array}$ & 30 & 3 & 60 \\
\hline 20 & Female & 5.70 & 19 & $\begin{array}{l}\text { Cough, tachypnea, } \\
\text { dyspnea, syncope, } \\
\text { crackles, heart murmur }\end{array}$ & I & 3 & 120 \\
\hline 21 & Female & 4.10 & 12 & $\begin{array}{l}\text { Cough, dyspnea, } \\
\text { crackles, heart murmur }\end{array}$ & I & 4 & I \\
\hline 22 & Male & 7.20 & 13 & $\begin{array}{l}\text { Exercise intolerance, } \\
\text { cough, dyspnea, } \\
\text { crackles, heart murmur }\end{array}$ & 180 & I & 2 \\
\hline 23 & Female & 3.10 & 12 & $\begin{array}{l}\text { Exercise intolerance, } \\
\text { cough, tachypnea, } \\
\text { dyspnea, syncope, } \\
\text { cyanosis, crackles, } \\
\text { heart murmur }\end{array}$ & 365 & 2 & 270 \\
\hline 24 & Female & 4.20 & 8 & $\begin{array}{l}\text { Cough, tachypnea, } \\
\text { dyspnea, crackles, } \\
\text { heart murmur }\end{array}$ & 730 & 2 & 265 \\
\hline 25 & Male & 7.30 & 10 & $\begin{array}{l}\text { Exercise intolerance, } \\
\text { tachypnea, dyspnea, } \\
\text { syncope, cyanosis, } \\
\text { crackles, heart murmur }\end{array}$ & 30 & 0 & 7 \\
\hline 26 & Male & 5.80 & 9 & $\begin{array}{l}\text { Tachypnea, } \\
\text { heart murmur }\end{array}$ & 180 & 3 & 365 \\
\hline 27 & Female & 4.40 & 11 & $\begin{array}{l}\text { Exercise intolerance, } \\
\text { cough, dyspnea, } \\
\text { heart murmur }\end{array}$ & 365 & 0 & 365 \\
\hline 28 & Male & 4.50 & 14 & $\begin{array}{l}\text { Exercise intolerance, } \\
\text { cough, heart murmur }\end{array}$ & 365 & 5 & 992 \\
\hline 29 & Male & 4.40 & 13 & $\begin{array}{l}\text { Exercise intolerance, } \\
\text { tachypnea, dyspnea, } \\
\text { syncope, cyanosis, } \\
\text { crackles, heart murmur }\end{array}$ & 180 & 3 & 14 \\
\hline
\end{tabular}


Table I (Continued)

\begin{tabular}{|c|c|c|c|c|c|c|c|}
\hline $\begin{array}{l}\text { Case } \\
\text { number }\end{array}$ & Sex & $\begin{array}{l}\text { Body mass } \\
(\mathrm{kg})\end{array}$ & $\begin{array}{l}\text { Age } \\
\text { (years) }\end{array}$ & $\begin{array}{l}\text { Historical and } \\
\text { clinical findings }\end{array}$ & $\begin{array}{l}\text { Duration of clinical } \\
\text { signs prior to } \\
\text { presentation (days) }\end{array}$ & $\begin{array}{l}\text { Radiological } \\
\text { cumulative } \\
\text { lung score }^{\mathrm{a}}\end{array}$ & $\begin{array}{l}\text { Survival (days) } \\
\text { from date of } \\
\text { diagnosis }\end{array}$ \\
\hline 30 & Male & 8.10 & 11 & $\begin{array}{l}\text { Exercise intolerance, } \\
\text { tachypnea, dyspnea, } \\
\text { syncope, cyanosis, } \\
\text { crackles, heart murmur }\end{array}$ & 14 & 4 & 14 \\
\hline 31 & Male & 4.30 & 11 & $\begin{array}{l}\text { Exercise intolerance, } \\
\text { tachypnea, dyspnea, } \\
\text { syncope, cyanosis, } \\
\text { crackles, heart murmur }\end{array}$ & 2 & 5 & 7 \\
\hline 32 & Male & 5.00 & 14 & $\begin{array}{l}\text { Exercise intolerance, } \\
\text { tachypnea, syncope, } \\
\text { cyanosis, crackles, heart } \\
\text { murmur }\end{array}$ & 21 & 0 & 210 \\
\hline 33 & Female & 6.18 & 12 & $\begin{array}{l}\text { Exercise intolerance, } \\
\text { cough, tachypnea, syncope, } \\
\text { cyanosis, crackles, } \\
\text { heart murmur }\end{array}$ & 150 & 2 & 210 \\
\hline 34 & Male & 6.00 & 8 & $\begin{array}{l}\text { Exercise intolerance, } \\
\text { syncope, cyanosis, } \\
\text { crackles, heart murmur }\end{array}$ & 60 & 3 & 150 \\
\hline 35 & Female & 5.00 & 11 & Coughing, heart murmur & 3 & 3 & 150 \\
\hline
\end{tabular}

Note: ${ }^{a} \mathrm{~A}$ cumulative lung severity score $(0-21)$ was the sum of the seven individual lung lobe scores.

\section{Bronchoscopy and BAL}

Bronchoscopy and BAL were performed in five dogs, and none of these dogs had obvious macroscopic changes consistent with chronic bronchial pathology except for thick inspissated mucus adhering to the bronchial walls of all dogs. The BAL cytology was consistent with inflammation in only two dogs with the predominant cellular component being neutrophils (range: $50 \%-80 \%$ ), with no organisms visible. Two of the five dogs, the same two dogs that had inflammatory cells recovered in the BAL and one dog with only macrophages, which was considered normal, had positive cultures of Klebsiella pneumoniae, Pseudomonas spp., and Candida albicans, respectively. No quantitative cultures were performed.

\section{Treatment}

All dogs were medicated chronically with sildenafil (Viagra, Pfizer) with doses ranging from 1.13 to $2.72 \mathrm{mg} / \mathrm{kg}$, orally three times daily for the treatment of PH. In addition, other drugs that were used to manage these dogs included antibiotics (amoxicillin-clavulanate, enrofloxacin), bronchodilators

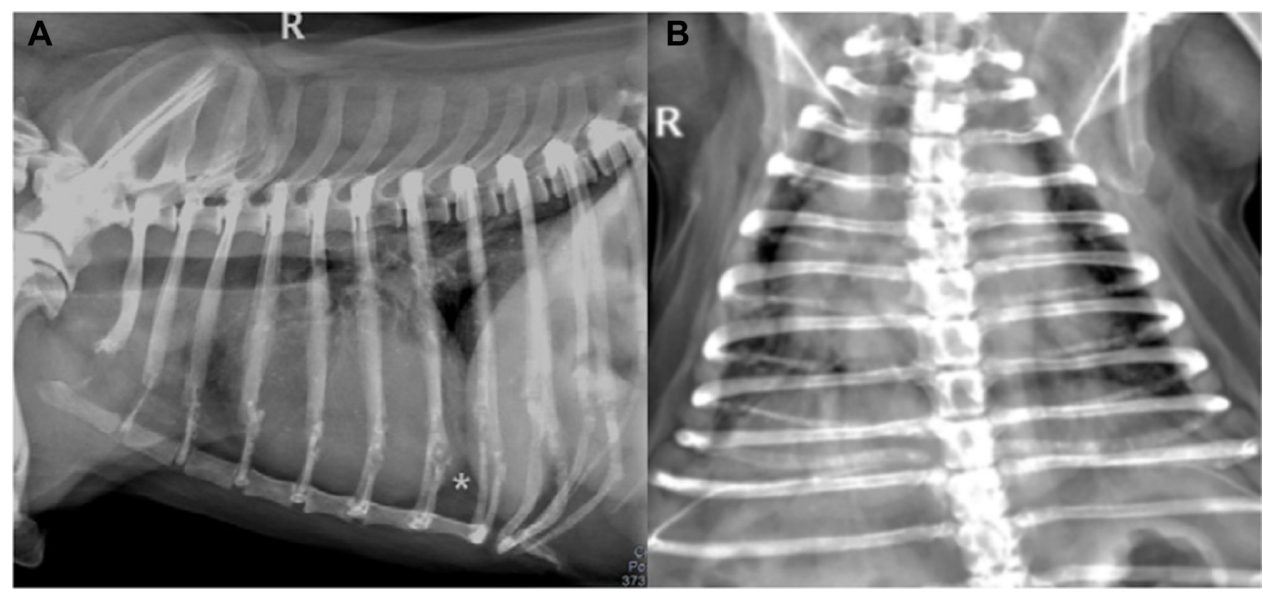

Figure I Thoracic radiographs of an obese 16-year-old male Pekinese with pulmonary hypertension and interstitial lung disease (case number 6).

Notes: (A) Right lateral recumbent and (B) dorsoventral views. There is a mild diffuse interstitial lung pattern, more so in the right caudal lung lobe. Right ventricular enlargement is present with elevation of the cardiac apex $(*)$ seen on the lateral view. The lung severity score was $6 / 21$. 


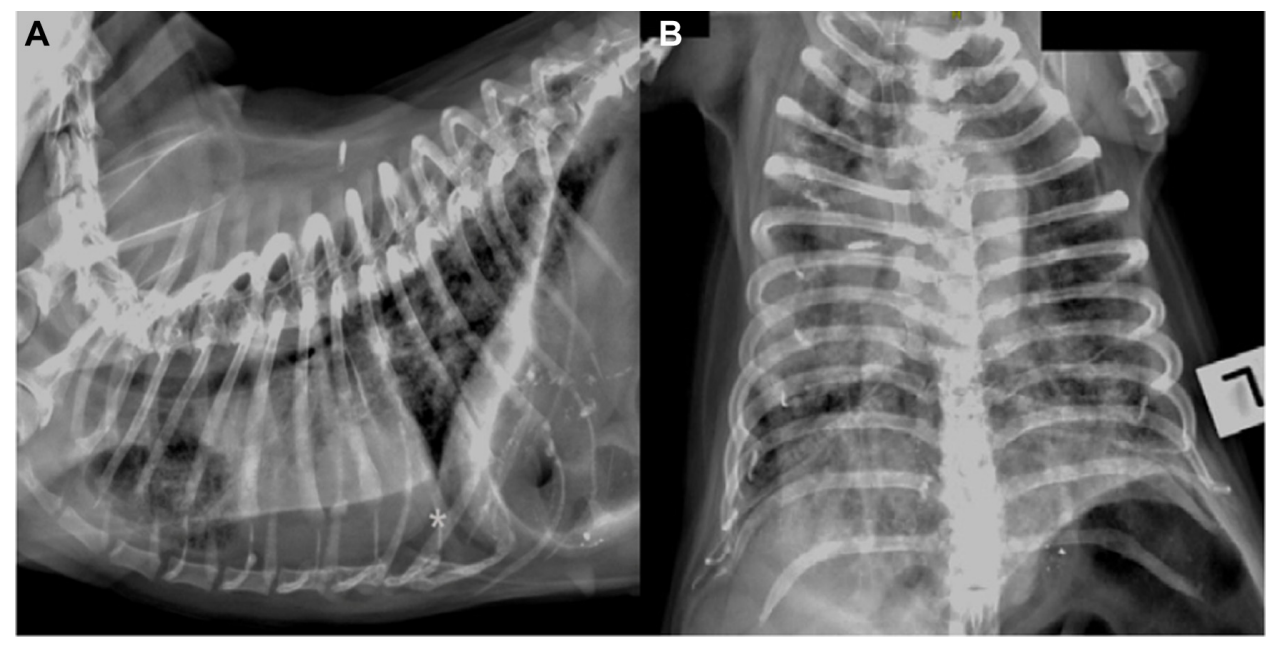

Figure 2 Thoracic radiographs of an obese 7-year-old female Pekingese (case number II) with pulmonary hypertension and interstitial lung disease.

Notes: (A) Right lateral recumbent and (B) dorsoventral views. Positioning is compromised due to severe respiratory effort limiting patient restraint. There is an advanced diffuse interstitial lung pattern, more so in the right lung lobes. Right ventricular enlargement is present with elevation of the cardiac apex $(*)$ seen on the lateral view. The main stem bronchi are compressed and dyspnea-induced marked gastrophagia is present. The lung severity score was $7 / 21$.

(theophylline), and oral (prednisolone) and inhaled corticosteroids (beclomethasone).

\section{Outcome}

By the end of the study period, 25 dogs had died as a consequence of the respiratory disease and were suffering from a respiratory crisis at the time of death. An additional two dogs were euthanized due to the grave prognosis (mortality rate $77 \%$ ). The recorded clinical signs in the medical record at the time of the death were either syncope or dyspnea. At the time of sampling completion, the median survival during the 3-year period was 60 days (IQR 9-210 days).

\section{Discussion}

This clinical case series describes 35 Pekingese that suffered from a chronic pulmonary parenchymal disease and associated $\mathrm{PH}$. There was an expected high mortality rate (77\%) and a short median survival from the time of diagnosis ( 60 days). This poor prognosis is not very different to previous reports of mortality associated with $\mathrm{PH}$ varying from 3 to 90 days, and these reports were of heterogeneous populations with severity thought to be worse in those cases having pulmonary etiologies (capillary). ${ }^{5,13}$ The incidence of this disease was assumed to be much higher in the population sampled as most of the 106 dogs could not be included in the study due to incomplete imaging records. Pekingese are a fairly popular
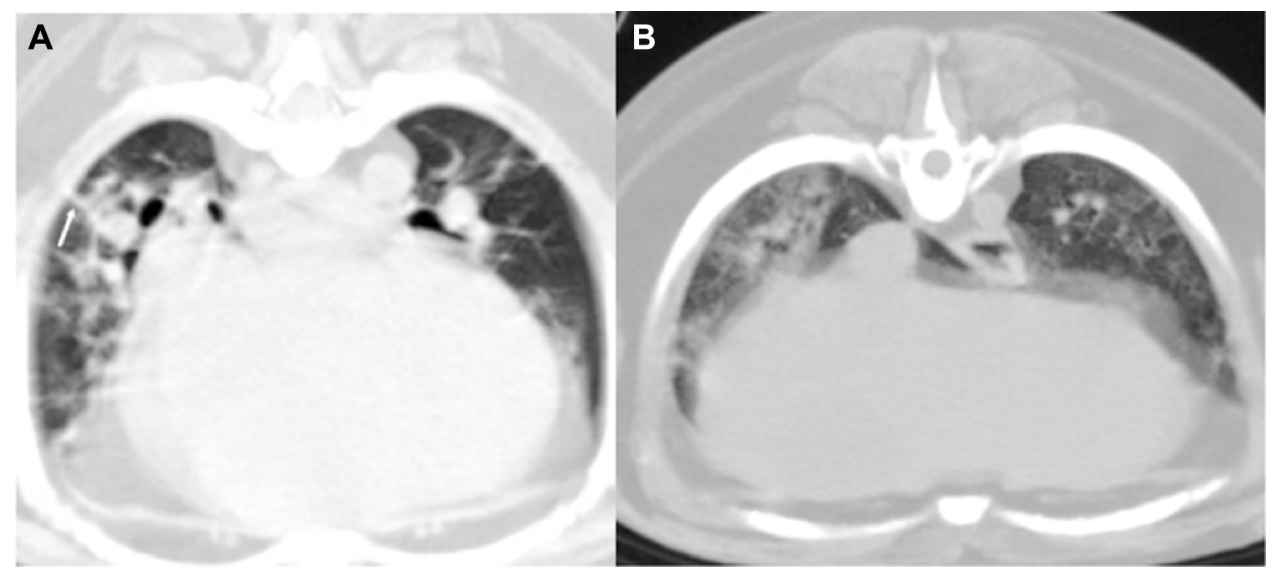

Figure 3 CT images in a lung window (window width I, I08 and window level -402) of an obese I6-year-old male Pekinese with pulmonary hypertension and interstitial lung disease (case number 6).

Notes: (A) Cranial at the level of the heart and (B) caudal at the level of the cranial liver transverse images. The right side of the dog is on the right of the images. The right side of the dog is on the left of the images. In (A), note the parenchymal bands (arrow) and honeycombing ventral to this. In (B), there is a more focal right caudal lobe dorsal ground-glass appearance indicative of early alveolar involvement. Note the more marked involvement of the right lung lobes.

Abbreviation: CT, computed tomography. 


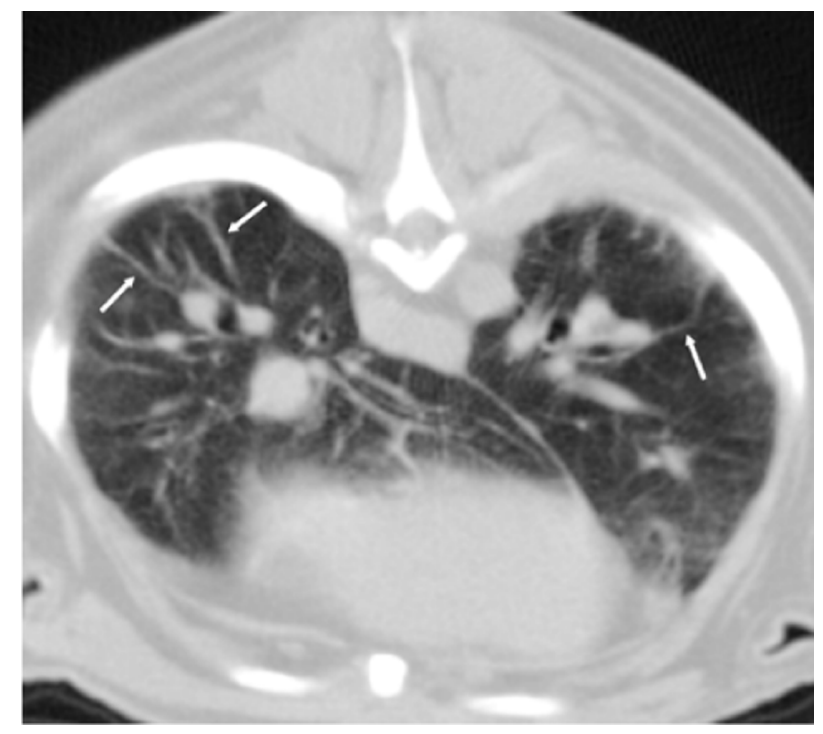

Figure $4 \mathrm{CT}$ transverse image in a lung window (window width I,607 and window level -499) made caudal the heart. This was an obese 16-year-old male Pekinese with pulmonary hypertension and interstitial lung disease (case number 6).

Notes: The right side of the dog is on the left of the image. Note the parenchymal bands (arrows) and diffuse interstitial reticular pattern.

Abbreviation: $\mathrm{CT}$, computed tomography.

breed in Hong Kong, but this alone is unlikely to account for the high incidence rate of this syndrome. This new described syndrome of an unknown etiology should be an important differential for dyspnea in this breed.

The most common cause of ILD in dogs is eosinophilic bronchopneumopathy (EBP) and is usually secondary to parasitic infections. ${ }^{14}$ Idiopathic pulmonary fibrosis (IPF) is the most frequently documented idiopathic ILD in dogs,

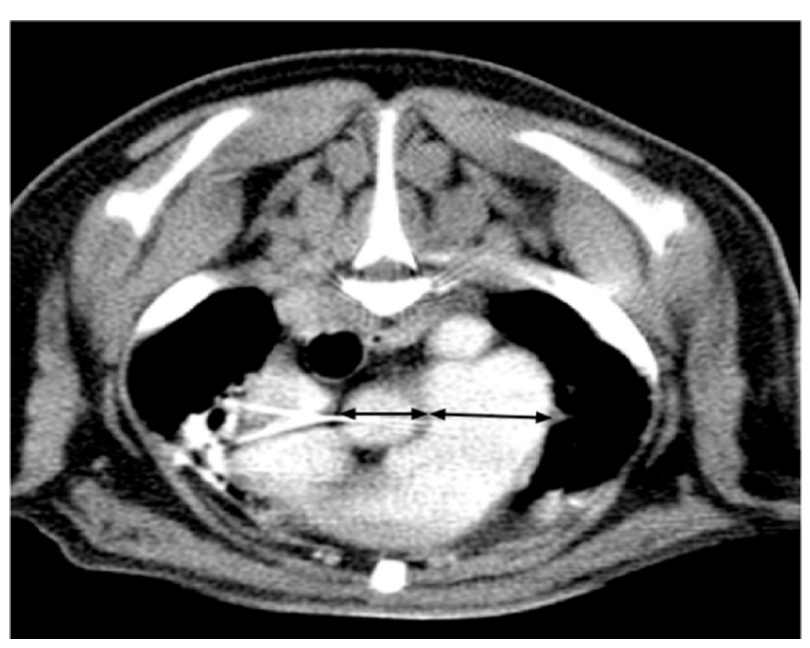

Figure 5 CT transverse post contrast image in a soft tissue window (window width 300 and window level 30) made through the heart at the level of the aortic (short arrow) and pulmonary trunks (long arrow). This was an obese 16-year-old male Pekinese with pulmonary hypertension and interstitial lung disease (case number 6). Notes: The dMPA:dAa was 1.6. The right side of the dog is on the left of the image. Abbreviations: CT, computed tomography; IMPA, main pulmonary artery diameter; $\mathrm{dAa}$, ascending aorta diameter.
Table 2 The radiographic and CT features of the five Pekingese diagnosed with pulmonary hypertension and interstitial lung disease

\begin{tabular}{|c|c|c|c|c|c|}
\hline Case number & 6 & 10 & II & 15 & 18 \\
\hline \multicolumn{6}{|l|}{ Radiographic } \\
\hline \multicolumn{6}{|l|}{ lung severity } \\
\hline \multicolumn{6}{|l|}{ score $(I-3)$} \\
\hline \multicolumn{6}{|l|}{ components } \\
\hline \multicolumn{6}{|l|}{$($ lobes I-7) } \\
\hline LI & I & I & 1 & 1 & I \\
\hline L2 & 0 & 0 & 1 & 0 & 0 \\
\hline L3 & 1 & I & I & 2 & 1 \\
\hline L4 & I & 1 & I & 0 & 0 \\
\hline L5 & I & 0 & I & I & I \\
\hline L6 & 2 & 1 & 1 & 0 & 0 \\
\hline L7 & 0 & 1 & 1 & 0 & 0 \\
\hline Total radiographic & 6 & 5 & 7 & 4 & 3 \\
\hline \multicolumn{6}{|l|}{ lung severity score ${ }^{b}$} \\
\hline \multicolumn{6}{|l|}{ Pulmonary artery- } \\
\hline \multicolumn{6}{|l|}{ to-vein ratio as } \\
\hline \multicolumn{6}{|l|}{ measured on } \\
\hline \multicolumn{6}{|l|}{ radiographs $^{c}$} \\
\hline $\mathrm{CrPA} / \mathrm{CrPV}$ & 2.43 & & 0.9 & & \\
\hline CdPA/CdPV & I & 1.07 & 1.3 & & 1.1 \\
\hline \multicolumn{6}{|l|}{$\mathrm{CT}$ determined } \\
\hline \multicolumn{6}{|l|}{ pulmonary artery } \\
\hline \multicolumn{6}{|l|}{ measurements } \\
\hline BA ratios $^{d}$ & 0.7 & & 0.93 & 0.79 & 0.73 \\
\hline $\mathrm{dMPA} / \mathrm{dAa}^{\mathrm{e}}$ & 0.86 & 1.35 & 1.63 & 0.76 & 1.15 \\
\hline \multicolumn{6}{|l|}{ CT lobe HUf } \\
\hline $\mathrm{LI}$ & -373 & -474 & -629 & -417 & -589 \\
\hline L2 & -559 & -539 & -703 & -165 & -565 \\
\hline L3 & -585 & -255 & $-64 \mid$ & -130 & -488 \\
\hline L4 & -294 & -314 & -596 & -713 & -695 \\
\hline L5 & -293 & -262 & -630 & -652 & -601 \\
\hline L6 & -304 & -158 & -626 & $-47 \mid$ & -375 \\
\hline L7 & -516 & $-|6|$ & -528 & -222 & -720 \\
\hline \multicolumn{6}{|l|}{ СТ\% affected ${ }^{g}$} \\
\hline $\mathrm{LI}$ & 47.7 & 33.5 & 11.8 & 41.5 & 17.4 \\
\hline L2 & 21.6 & 24.4 & 1.4 & 76.9 & 20.8 \\
\hline L3 & 17.9 & 64.2 & 10.1 & 81.8 & 31.6 \\
\hline L4 & 58.8 & 56.0 & 16.4 & 0.0 & 2.5 \\
\hline L5 & 58.9 & 63.3 & 11.6 & 8.6 & 15.7 \\
\hline L6 & 57.4 & 77.8 & 12.2 & 33.9 & 47.4 \\
\hline L7 & 27.6 & 77.4 & 25.9 & 68.8 & -1.0 \\
\hline \multicolumn{6}{|l|}{$C T$ total lung lobe } \\
\hline \multicolumn{6}{|l|}{ involvement ${ }^{h}$} \\
\hline $\mathrm{LI}$ & 3.8 & 1.3 & 0.9 & 3.3 & 0.7 \\
\hline L2 & 0.5 & 0.6 & 0.1 & 5.3 & 0.5 \\
\hline L3 & 1.3 & 9.4 & 1.5 & 18.0 & 4.7 \\
\hline L4 & 7.4 & 7.1 & 2.1 & 0.0 & 0.2 \\
\hline L5 & 4.3 & 2.3 & 0.8 & 0.3 & 1.2 \\
\hline L6 & 8.0 & 16.3 & 1.7 & 2.4 & 6.6 \\
\hline L7 & 0.7 & 6.2 & 1.4 & 5.5 & -0.0 \\
\hline $\mathrm{CT}$ total lung & 26.2 & 43.3 & 8.5 & 34.9 & 13.7 \\
\hline \multicolumn{6}{|l|}{ nonaeration } \\
\hline index & & & & & \\
\hline General CT & & & & & \\
\hline findings & & & & & \\
\hline
\end{tabular}

(Continued) 
Table 2 (Continued)

\begin{tabular}{|c|c|c|c|c|c|}
\hline Case number & 6 & 10 & I I & 15 & 18 \\
\hline $\begin{array}{l}\text { Traction } \\
\text { bronchiectasis }\end{array}$ & Yes & Yes & No & No & Yes \\
\hline $\begin{array}{l}\text { Peribronchovascular } \\
\text { interstitial thickening }\end{array}$ & Yes & Yes & Yes & No & Yes \\
\hline Subpleural thickening & Yes & No & No & No & No \\
\hline Nodules & Yes & No & No & No & No \\
\hline $\begin{array}{l}\text { Consolidated lung } \\
\text { obscuring pulmonary } \\
\text { vessels }\end{array}$ & Yes & Yes & No & No & No \\
\hline Honeycombing & Yes & Yes & No & No & Yes \\
\hline Parenchymal bands & Yes & No & Yes & No & Yes \\
\hline Cavitatory lesions & No & No & No & No & No \\
\hline $\begin{array}{l}\text { Incidental findings } \\
\text { on imaging }\end{array}$ & & $\begin{array}{l}\text { Tracheal, } \\
\text { main stem } \\
\text { and } \\
\text { accessory } \\
\text { bronchus } \\
\text { collapse }\end{array}$ & & $\begin{array}{l}\text { Pectus } \\
\text { excavatum } \\
\text { displacing } \\
\text { the heart } \\
\text { to the left }\end{array}$ & \\
\hline
\end{tabular}

Notes: Specifically the components of the lung pathological involvement severity scoring system and the total lung nonaeration index as calculated using radiographic and CT images respectively. ${ }^{\mathrm{L}} \mathrm{LI}$ pars cranialis left cranial lung lobe; L2 pars caudalis left cranial lung lobe; L3 left caudal lung lobe; L4 right cranial lung lobe; L5 right middle lung lobe; L6 right caudal lung lobe; L7 accessory lung lobe. ${ }^{\mathrm{t}}$ The sum of score ( $0-3$, with 0 being no lung pattern and 3 being an alveolar pattern) assigned to each lung lobe $(\mathrm{LI}-\mathrm{L7})$ on radiographic interpretation. Maximum score $=2 \mathrm{I}$. ${ }^{\mathrm{c}} \mathrm{The}$ ratio of the left cranial lobar pulmonary artery to adjacent vein at the level of the fourth intercostal space on lateral thoracic radiograph $(\mathrm{CrPA} / \mathrm{CrPV})$ and the ratio of the left or right caudal lobar pulmonary artery at the level of the eleventh intercostal rib on dorsoventral thoracic radiograph (CdPA/CdPV). Internal bronchial lumento-adjacent pulmonary arterial (BA) ratio. The main pulmonary artery diameter (dMPA), measured on transverse view at just distal to the bifurcation, and ascending aorta diameter $(\mathrm{dAa})$ were measured using electronic calipers on the same transverse slice, and a ratio was determined. ${ }^{\mathrm{C}} \mathrm{CT} \mathrm{HU}$, the Hounsfield unit value of the lung lobe. ${ }^{\mathrm{B}} \mathrm{CT} \%$ affected is the inverse\% of aeration. ${ }^{\mathrm{h}}$ Refers to the amount of lung affected by pathology, depending on the contribution the lobe makes to overall lung volume. 'Total lung nonaeration index is the sum of the lung involvement of lung lobes LI-L7.

Abbreviations: $\mathrm{CT}$, computed tomography; CrPA/CrPV, cranial lobar pulmonary artery and vein; CdPA/CdPV, caudal lobar pulmonary artery and vein.

although a rare disease, and a cause of $\mathrm{PH}$, which has been not only well documented in the West Highland white terrier (WHWT) but also described in other terrier breeds. ${ }^{15-17}$ Other types of idiopathic ILD have been described in case reports or case series and include histiocytosis X, cryptogenic organizing pneumonia (COP), sarcoidosis, hypersensitivity pneumonitis, steroid-responsive pneumonitis, pulmonary alveolar proteinosis, Sjögren's syndrome, silicosis, and asbestosis. ${ }^{1,3,18}$ Pulmonary parenchymal diseases, both alveolar and ILD, reported to cause PH include IPF, chronic pulmonary disease, mineralization, neoplasia, and, parasitic causes (D. immitis and Angiostrongylus vasorum) ${ }^{5,8,19,20}$ Rare idiopathic ILDs in dogs are diagnosed by a combination of signalment, the chronic nature of the disease, clinical findings, imaging studies, including thoracic radiographs and CT, and exclusion of other causes of cardiac and respiratory pathology and finally confirmed with histopathology of a lung biopsy.
The accompanying PH in these Pekingese is indicative of the severity and chronicity of the pulmonary parenchymal disease. There are many parallels between this syndrome in geriatric Pekingese and IPF in WHWT, the best characterized of the ILD, but none of the pathology described is specific for IPF and further IPF is not steroid responsive. ${ }^{21,22}$ Other rare ILDs should be considered as differentials that share many of the same clinical and radiological findings. Cytology of $\mathrm{BAL}$ and/or radiographic findings can differentiate some of these ILDs. EBP could have alveolar, interstitial, or bronchial lung pattern, but BAL is distinctive in that there is an overwhelming eosinophilic inflammation. ${ }^{23} \mathrm{CT}$ findings in EBP include pulmonary parenchymal abnormalities, specifically ground-glass pattern, consolidation, and nodules, bronchial wall thickening, plugging of the bronchial lumen by mucous, bronchiectasis, and lymphadenopathy. ${ }^{24}$ The most commonly reported thoracic radiographic findings in WHWT with IPF were a bronchointerstitial pattern and patchy alveolar opacities with indistinct margins in one or two lung lobes, a wide distribution throughout the lung field of an interstitial lung pattern, and bronchial markings with right-sided heart enlargement. ${ }^{15,19,23}$ Histiocytosis $\mathrm{X}$ is characterized by nodular infiltrates on radiographs and atypical histiocytes on BAL; sarcoidosis is typified by lymphadenopathy, bullae, and cysts with epitheliod cells, multinucleated giant cells, with lymphocytes and plasma cells on BAL. ${ }^{3}$ The radiographic pattern in two dogs with steroid-responsive pneumonitis had patchy alveolar opacities and a diffuse bronchointerstitial lung pattern. ${ }^{18}$ The dogs in our study predominantly had a diffuse interstitial to bronchointerstitial mixed pattern and rarely patchy alveolar infiltrates. More recently, a number of biomarkers measured on BAL fluid have shown promise in identifying ILD, specifically IPF in WHWT including chemokines such as CCL2. ${ }^{25}$ ILD appears to be the most likely cause of the pulmonary parenchymal disease in this group of Pekingese based on the chronic history, the associated $\mathrm{PH}$, the soft crackles audible on auscultation, and nonspecific imaging findings. A notable feature in our case series was the report of audible pulmonary crackle on auscultation, similar to the velcro crackle described in many ILDs described in humans. An alternative explanation is that the pulmonary lesions visible radiographically correspond to the noncardiogenic pulmonary alveolar infiltrates that are associated with PH that develop in a diffuse patchy distribution, suspected to be interstitial pulmonary fibrosis recently described in ten dogs. ${ }^{26}$ These have been described to resolve with the treatment with sildanefil. The dogs in that case study presented with acute onset of dyspnea, syncope, 
in conjunction with an audible heart murmur, as is the case in the dogs described in our study.

The mean age at presentation of this group of Pekingese (14.5 years; range: 7-19 years) was slightly older than WHWT with IPF. ${ }^{46,13}$ Pekingese had a history of exercise intolerance or syncope up to 255 days prior to presentation indicative of an underlying chronic ILD. Clinical findings included tachypnea, dyspnea, syncope, and cyanosis. Coughing was not a very significant feature in the history or clinical findings. Clinical findings in the ILD reports included at least one of the following: coughing, exercise intolerance, breathlessness, tachypnea, syncope, and collapse. ${ }^{21,27}$

A recent publication reported that the mean $\mathrm{CrPV} / \mathrm{CrPA}$ and $\mathrm{CdPV} / \mathrm{CdPA}$ in dogs without cardiac disease (controls) were $0.99 \pm 0.6$ and $1.04 \pm 0.19$, respectively, as the focus of the study was venous congestion..$^{28}$ Our study measured arterial-to-venous ratios as pulmonary artery dilation is the main vascular radiological pattern of $\mathrm{PH}$. An additional discrepancy between this paper and ours was that our CdPA/ CdPV measurements were made at the level of the ninth as opposed to the eleventh intercostal space. When the control dogs from the previous study had their mean CrPV and CdPV to respective artery ratios inverted, the mean ratios (1.01 and 0.96 , respectively) were very similar to our measure of CrPA and CdPA to vein ratios (1.1, IQR 0.97-1.4; $\mathrm{n}=21$ and 1.0, IQR $1.0-1.3 ; \mathrm{n}=18)$. The evaluation of the cranial and caudal lobar pulmonary arteries and the ratios of these arteries relative to the adjacent veins offered very little diagnostic value in detecting severe $\mathrm{PH}$ in our dogs.

CT detected several lung lesions, with the majority located in the dorsocaudal lung lobes. The unique CT pattern of IPF is described as ground-glass, parenchymal bands, subpleural lines, moderate subpleural interstitial thickenings, moderate peribronchiolar interstitial thickening, consolidation, traction bronchiectasis, and honeycombing. ${ }^{17,19}$ The $\mathrm{CT}$ findings in the few reported cases of canine COP and steroid-responsive pneumonitis were bilateral asymmetric areas of air space consolidation and multifocal subpleural and peribronchial poorly defined nodular opacities, ground-glass opacities, and parenchymal bands. ${ }^{18,27}$ The five dogs that underwent CT had all the described patterns of ILD. An association in IPF has been reported between the number of lobes affected with ground-glass appearance and interstitial lung pathology on CT becoming more diffuse in pattern as the clinical disease worsened. ${ }^{17}$ Subpleural interstitial thickening, parenchymal bands, and peribronchovascular interstitial thickening are associated with moderate and severe stage of IPF, and traction bronchiectasis is found in the severest form of the disease. ${ }^{17}$
In human CT studies, it has been established that the diameters and cross-sectional area of the pulmonary arteries measured from $\mathrm{CT}$ scans can be used as an indicator of $\mathrm{PH}$ and as an index for calculating pulmonary artery pressure noninvasively, but in pulmonary fibrosis and other ILDs, the pulmonary artery can dilate without $\mathrm{PH}$ and does not become a reliable predictor. ${ }^{29-31}$ Thus, a potentially more reliable index for PH in patients with pulmonary fibrosis and other causes of ILD is the ratio of the IMPA to the dAa examined on the same transverse slice of the level of the pulmonary artery bifurcation and the widest short-axis $\mathrm{dAa}$, and the mean ratio was found to be $1.1 .^{30} \mathrm{~A}$ later study found that the diameter of the PA and the cross-sectional area of the PA as a ratio to the ascending aorta correlated equally well to the invasive PA measurement. ${ }^{32}$ Our dogs had a mean ratio of 1.1 (range: 0.86-1.63), and the value of this ratio still needs to be determined in dogs. Pulmonary artery diameters (average of the left and right pulmonary arteries) have also found to be predictive of death in patients with $\mathrm{PH}$ and bronchiectasis. ${ }^{33} \mathrm{CT}$ reconstructions using multiplanar reformatting of the RV and left ventricular volumes can be calculated and compared. The RV to left ventricular volume ratios have been shown to correlate well with pulmonary artery pressures measured by cardiac catheterization $(R=0.82, P<0.001) .{ }^{34} \mathrm{In}$ our study, multiplanar reformatting was not possible, but in three dogs, the average ratio of $\mathrm{RV}$ to left ventricular internal diameter was $106 \%$; considering the right ventricle should be $<50 \%$ of the left ventricular internal diameter, this value was considered significant. Thus, a number of noninvasive CT measurements can be used to predict $\mathrm{PH}$ in people. The application of thoracic CT for noninvasively assessing the pulmonary arteries in dogs has already standardized the pulmonary artery size, using the bronchial lumen (internal diameter) at the same CT section as a reference, measured at the level of the fourth and eleventh ribs for the cranial and caudal lobar arteries, respectively, with BA ratios in normal dogs having a mean of $1.45 \pm 0.21(99 \%$ confidence interval [CI] 1.34-1.56). ${ }^{12}$ The mean BA in our study, using the identical measurements $(\mathrm{n}=6)$, was 0.72 (range: $0.5-0.93$ ), indicative of significant larger pulmonary arteries in our group of dogs as compared to the study by Cannon et al and should be considered as a potential $\mathrm{CT}$ index in predicting PH (2009).

In the five dogs that had bronchoscopy and BAL performed, there was no endoscopic evidence of traction bronchiectasis, and the cytology was consistent with a neutrophilic inflammation in only two dogs $(50 \%-80 \%$ neutrophils). Bronchoscopy changes in IPF have been 
described as irregular mucosa, bronchial mucous, mild bronchiectasis, bronchomalacia; bacteria are not demonstrated on bronchoalveolar cytology or cultured, and in the four of the five dogs that had cellular BAL samples, neutrophils $(50 \%-80 \%)$ predominated with macrophages $(84 \%)$ in the other; although this is considered a normal cell type, the remainder $(15 / 20)$ did not have any significant inflammation. ${ }^{13}$ In contrast, BAL cytology in EBP is consistent with an abnormal eosinophilia. ${ }^{14}$

\section{Limitations}

The main limitation of this study is the lack of lung histopathology and is due to the cultural opposition to necropsy in the region. Lung biopsy is associated with a high complication rate and mortality; two of eleven dogs and one of three dogs with ILD in two case series died as a complication. ${ }^{16,35}$ Lung biopsy was not offered to any of the clients due to the severe respiratory compromise of the dogs at the time of diagnosis. Anecdotally, a number of etiologies and pathogenesis including pollution and chronic high-pressure dynamics induced from chronic brachycephalic obstructive airway syndrome are possibilities. It cannot be established what the true prevalence of $\mathrm{PH}$ and chronic idiopathic ILD is in Pekingese without syncope and dyspnea as these dogs are unlikely to present to a veterinarian as chronic exercise intolerance could be assumed to be due to old age or brachycephalic obstructive airway syndrome. Ideally, a prospective study recruiting middle-aged Pekingese and performing sequential thoracic radiographs and echocardiography should be implemented. Postmortem with histopathology of the lungs should be able to elucidate the etiology of this syndrome but may prove difficult in this region.

\section{Acknowledgments}

The authors would like to acknowledge the following people for their contribution: the veterinary staff at Peace Avenue Veterinary Clinic, Kowloon, Hong Kong (PAVC, HK) for their assistance in the diagnostic imaging and ICU management in these cases, Mr Kenny Tang (PAVC, HK) for assisting in the medical record data search and DICOM images acquisition, and Ms Ermine Cotton, RUSVM Library Services, in locating many journal articles by interlibrary loans.

\section{Disclosure}

The authors report no conflicts of interest in this work.

\section{References}

1. Cohn LA. Pulmonary Parenchymal Diseases. Textbook of Veterinary Internal Medicine. 7th ed. Expert Consult; Elsevier Saunders, St Louis, Mo: 2010.
2. Crystal RG, Bitterman PB, Rennard SI, Hance AJ, Keogh BA. Interstitial lung diseases of unknown cause. Disorders characterized by chronic inflammation of the lower respiratory tract. $N$ Engl J Med. 1984;310(4):235-244.

3. Norris CR, Griffey SM, Walsh P. Use of keyhole lung biopsy for diagnosis of interstitial lung diseases in dogs and cats: 13 cases (1998-2001). $J$ Am Vet Med Assoc. 2002;221(10):1453-1459.

4. Cordier JF. Cryptogenic organising pneumonia. Eur Respir J. 2006; 28(2):422-446.

5. Johnson L, Boon J, Orton EC. Clinical characteristics of 53 dogs with Doppler-derived evidence of pulmonary hypertension: 1992-1996. J Vet Intern Med. 1999;13(5):440-447.

6. Johnson L. Diagnosis of pulmonary hypertension. Clin Tech Small Anim Pract. 1999;14(4):231-236.

7. Fleming E, Ettinger SJ. Pulmonary hypertension. Compend Contin Educ Vet. 2006;28(10):720-722,724-730.

8. Kellihan HB, Stepien RL. Pulmonary hypertension in dogs: diagnosis and therapy. Vet Clin North Am Small Anim Pract. 2010;40(4):623-641.

9. Glaus TM, Tomsa K, Hassig M, Reusch C. Echocardiographic changes induced by moderate to marked hypobaric hypoxia in dogs. Vet Radiol Ultrasound. 2004;45(3):233-237.

10. Atkins $\mathrm{C}$, Bonagura J, Ettinger S, et al. Guidelines for the diagnosis and treatment of canine chronic valvular heart disease. J Vet Intern Med. 2009;23:8.

11. Yilmaz C, Ravikumar P, Dane DM, Bellotto DJ, Johnson RL Jr, Hsia CC. Noninvasive quantification of heterogeneous lung growth following extensive lung resection by high-resolution computed tomography. J Appl Physiol (1985). 2009;107(5):1569-1578.

12. Cannon MS, Wisner ER, Johnson LR, Kass PH. Computed tomography bronchial lumen to pulmonary artery diameter ratio in dogs without clinical pulmonary disease. Vet Radiol Ultrasound. 2009;50(6): 622-624.

13. Bach JF, Rozanski EA, MacGregor J, Betkowski JM, Rush JE. Retrospective evaluation of sildenafil citrate as a therapy for pulmonary hypertension in dogs. J Vet Intern Med. 2006;20(5):1132-1135.

14. Corcoran BM, Thoday KL, Henfrey JI, Simpson JW, Burnie AG, Mooney CT. Pulmonary infiltration with eosinophils in 14 dogs. J Small Anim Pract. 1991;32(10):494-502.

15. Corcoran BM, Cobb M, Martin MWS, et al. Chronic pulmonary disease in West Highland white terriers. Vet Rec. 1999;144(22):611-616.

16. Lobetti RG, Milner R, Lane E. Chronic idiopathic pulmonary fibrosis in five dogs. J Am Anim Hosp Assoc. 2001;37(2):119-127.

17. Johnson VS, Corcoran BM, Wotton PR, Schwarz T, Sullivan M. Thoracic high-resolution computed tomographic findings in dogs with canine idiopathic pulmonary fibrosis. J Small Anim Pract. 2005;46(8):381-388.

18. Koster L, Kirberger R. Steroid-responsive idiopathic interstitial lung disease in two dogs. Vet Rec Case Rep. 2014;2(1):e000091.

19. Heikkila HP, Lappalainen AK, Day MJ, Clercx C, Rajamaki MM. Clinical, bronchoscopic, histopathologic, diagnostic imaging, and arterial oxygenation findings in West Highland white terriers with idiopathic pulmonary fibrosis. J Vet Intern Med. 2011;25(3):433-439.

20. Nicolle AP, Chetboul V, Tessier-Vetzel D, Sampedrano CC, Aletti E, Pouchelon JL. Severe pulmonary arterial hypertension due to Angiostrongylosus vasorum in a dog. Can Vet J. 2006;47(8):792-795.

21. Mandel J, Mark EJ, Hales CA. Pulmonary veno-occlusive disease. Am J Respir Crit Care Med. 2000;162(5):1964-1973.

22. Montani D, Achouh L, Dorfmuller P, et al. Pulmonary veno-occlusive disease: clinical, functional, radiologic, and hemodynamic characteristics and outcome of 24 cases confirmed by histology. Medicine. 2008;87(4):220-233.

23. Corcoran BM, Thoday KL, Henfry JI, Simpson JW, Burnie AG, Mooney CT. Pulmonary infiltrates of eosinophils in 14 dogs. J Small Anim Pract. 1991;32:9.

24. Mesquita L, Lam R, Lamb CR, McConnell JF. Computed tomographic findings in 15 dogs with eosinophilic bronchopneumopathy. Vet Radiol Ultrasound. 2015;56(1):33-39. 
25. Roels E, Krafft E, Farnir F, et al. Assessment of CCL2 and CXCL8 chemokines in serum, bronchoalveolar lavage fluid and lung tissue samples from dogs affected with canine idiopathic pulmonary fibrosis. Vet J. 2015;206(1):75-82.

26. Kellihan HB, Waller KR, Pinkos A, Steinberg H, Bates ML. Acute resolution of pulmonary alveolar infiltrates in $10 \mathrm{dogs}$ with pulmonary hypertension treated with sildenafil citrate: 2005-2014. J Vet Cardiol. 2015;17(3):182-191.

27. Phillips S, Barr S, Dykes N, et al. Bronchiolitis obliterans with organizing pneumonia in a dog. J Vet Intern Med. 2000;14(2):204-207.

28. Oui H, Oh J, Keh S, et al. Measurements of the pulmonary vasculature on thoracic radiographs in healthy dogs compared to dogs with mitral regurgitation. Vet Radiol Ultrasound. 2015;56(3):251-256.

29. Kuriyama K, Gamsu G, Stern RG, Cann CE, Herfkens RJ, Brundage BH. CT-determined pulmonary artery diameters in predicting pulmonary hypertension. Invest Radiol. 1984;19(1):16-22.

30. Devaraj A, Wells AU, Meister MG, Corte TJ, Hansell DM. The effect of diffuse pulmonary fibrosis on the reliability of CT signs of pulmonary hypertension. Radiology. 2008;249(3):1042-1049.
31. Abel E, Jankowski A, Pison C, Luc Bosson J, Bouvaist H, Ferretti GR Pulmonary artery and right ventricle assessment in pulmonary hypertension: correlation between functional parameters of ECG-gated CT and right-side heart catheterization. Acta Radiol. 2012;53(7):720-727.

32. Devaraj A, Wells AU, Meister MG, Corte TJ, Wort SJ, Hansell DM. Detection of pulmonary hypertension with multidetector CT and echocardiography alone and in combination. Radiology. 2010; 254(2):609-616.

33. Devaraj A, Wells AU, Meister MG, Loebinger MR, Wilson R, Hansell DM. Pulmonary hypertension in patients with bronchiectasis: prognostic significance of CT signs. AJR Am J Roentgenol. 2011;196(6): 1300-1304.

34. Lee H, Kim SY, Lee SJ, Kim JK, Reddy RP, Schoepf UJ. Potential of right to left ventricular volume ratio measured on chest $\mathrm{CT}$ for the prediction of pulmonary hypertension: correlation with pulmonary arterial systolic pressure estimated by echocardiography. Eur Radiol. 2012;22(9):1929-1936.

35. Norris AJ, Naydan DK, Wilson DW. Interstitial lung disease in West Highland white terriers. Vet Pathol. 2005;42(1):35-41.

\section{Publish your work in this journal}

Veterinary Medicine: Research and Reports is an international, peer-reviewed, open access journal publishing original research, case reports, editorials, reviews and commentaries on all areas of veterinary medicine. The manuscript management system is completely online and includes a very quick and fair peer-review system.
Visit http://www.dovepress.com/testimonials.php to read real quotes from published authors. 